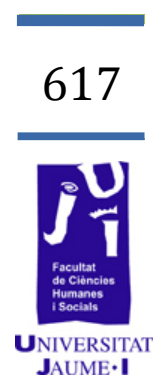

\title{
Teaching secondary students ICC through music. A teaching proposal
}


This paper aims at supplying some guidelines related to contents and methodology that might be implemented to teach ICC in secondary school. First, a theoretical introduction is provided. After that, the proposal is fully explained. Then, assessment is discussed and, finally, conclusions are drawn and expected learning outcomes described.

The teaching proposal that is going to be described takes as its leading theme the history of (pop) music in English speaking countries during the second half of the $20^{\text {th }}$ century, from the 1960 s to the end of the century. It has been devised to be carried out in a Spanish secondary education institution, either public or private (students aged between 12 and 16) in an intact classroom; therefore, the number of participants could range from twenty-five to thirty-six pupils (Generalitat Valenciana, Conselleria d'Educació, Cultura i Esports, 2014). All the classes will carry out the same type of tasks, although each one will be focused on a different decade, in terms of topic and information.

The project could be carried out as a part of English as a Foreign Language (EFL), by devoting one weekly class session (out of three) to it, and leaving the other two for strict language instruction. This option has the advantage of benefitting all the students in the class, since EFL is a compulsory subject in secondary education in Spain. On top of that, it could easily be included in the regular schedule of the subject.

Key words: intercultural, communication, English, secondary, education, music.

\section{Introduction}

\subsection{Intercultural Communication Competence: the relationship between language and culture}

Languages are not spoken in the void; they belong to a community of speakers, which has a culture of its own (history, arts, politics, educational system, etc.), social conventions, and so on (Celce-Murcia, 2007). All of these factors affect languages and the way they are used in interaction.

For most scholars "language and culture are seen as inseparable in the learning process» (Byram \& Feng, 2004, p. 161) for a number of reasons. First, "language is the vehicle of culture and (...) categorizes reality according to its corresponding culture» (Hofstede, 1986, p. 314). Moreover, according to Xue (2014), culture influences communication in a double sense. On the one hand, each cultural system encourages a particular communicative style. On the other hand, it has the power to shape perception. As a result, language teaching should also entail culture teaching, so that communication can be successful. Furthermore, culture 
has been demonstrated to even have an impact on the learning style, on "a person's preference for abstract conceptualization versus concrete experience» (Joy \& Kolb, 2009, p. 83). If culture is connected to such an intimate variable as this, it might also be linked to other aspects. However, the truth is that, very often, "the "teaching of and about culture" seems to be neglected» (Young \& Sachdev, 2011, p. 95).

Educational legal directions often include guidelines concerning culture and language which, despite highlighting their importance, end up being too vague. If we focus, for example, on the European framework, the European Commission $(2006,2007)$ refers to a number of key competences for lifelong learning in the European Reference Framework, which are closely related to intercultural understanding: communication in foreign languages, social and civic competences, and cultural awareness and expression. The general directions provided by the European Commission have been reflected in the different laws of education of the member countries and, to illustrate one such case, the Spanish example will be dealt with more thoroughly below.

Spanish education is going through a time of change, since a new Law of Education is being implemented at the moment. As a result, depending on the year of instruction, the law which is applied to it differs. During the present academic year (2015/2016) the new Law of Education (LOMCE) affects the first and third years of secondary education, whereas the second and fourth are regulated by the old one (LOE), so one might expect improvements in the way in which different issues are presented. However, one of the things they have in common is how the aforementioned topic is dealt with. The old Spanish Law of Education (Real Decreto 1631/2006, 29th December), for example, does not limit learning a foreign language to the language itself; it also encourages the development of intercultural awareness as a means for understanding global issues. According to this law, the goals connected to Intercultural Communication Competence (ICC) that should be present in the foreign language (FL) curriculum are:

- To know and critically interpret multilingual and multicultural diversity in order to develop a positive attitude towards linguistic diversity, regarded as a cultural wealth;

- To reflect about the different social customs to adopt effective strategies which allow them to communicate in different social and cultural contexts, regarding foreign languages as means of communication and understanding among people from different origins, languages and cultures, and avoiding linguistic stereotypes linked to any kind of prejudice. (Real Decreto 1631/2006, 29th December).

On the other hand, in the new Law of Education (Real Decreto $1105 / 2014$, 26th December) it is admitted that both socio-civic competences and cultural expression are an integral part of intercultural competence and, as such, they should be inherent to learning foreign languages. As a result, among the teaching goals that are contemplated in 
the subject of English as a Foreign Language, the following is included: «integrating the most relevant socio-cultural and sociolinguistic aspects of the target language in the student's own intercultural competence» in order to get beyond the differences and stereotypes, as well as to avoid mistakes which lead speakers to potentially conflictive situations.

Regardless of which law is in force, in spite of the legal formulation that is employed, a simple question could be posed here: what does that mean, in terms of specific content to be taught in a classroom? Or, in other words, how is a teacher supposed to translate those words into his/ her daily practice? All in all, teaching ICC does not seem to be an easy task due to several circumstances. First, although, generally speaking, ICC is mentioned in most curricula, those curricula provide excessively general intercultural learning goals and «fail to indicate how these general goals are to be taught» (Fageeh, 2011, p. 66). Consequently, teachers usually find themselves with a total lack of precise information on what to teach and how to do it.

Moreover, ICC is usually learnt as part of another subject. Most of the times, it is included in the FL class (Fageeh, 2011). The problem here is that attaining culture goals usually comes second to attaining linguistic objectives (grammar, vocabulary, pronunciation, etc.), which are usually the real target in most courses. If we take official examinations as an example (university entrance exams, Cambridge, Official School of Languages, etc.), there are no sections devoted to assessing the learners' IC competence. Therefore, not being real "content" for exams, it is often skipped or "left for tomorrow".

Another obstacle that may be encountered when trying to instruct students in ICC is the lack of appropriate materials. Those teachers who use textbooks, for example, often find serious weaknesses in their cultural content. Some of the most frequently mentioned are the absence of controversial social issues, a tourism-oriented view of the foreign society, abundant stereotyping, or excessive focus on language form (Skopinskaja, 2003), to name but a few of them. As a result, materials are often replaced or, simply, censored, because they fail to provide suitable resources. Consequently, the cultural view they offer might be biased or incomplete.

\subsection{Developing ICC in the secondary school}

As previously stated, in spite of agreeing on its importance to carry out successful communication, ICC is not always dealt with properly in foreign language teaching. In the following sections, some guidelines will be provided on what to include (contents) and how to instruct learners (methodological hints) in order to deepen their insight on the matter.

\subsubsection{What to teach: contents}

If a teacher took Ferraro's (1995, as quoted in Xue, 2014, p. 1493) allencompassing definition of culture as «everything that people have, 
think, and do as member of a society", he/ she would probably feel overwhelmed when facing the task of teaching culture to his/ her students. That apparently simple concept covers everything: objects, beliefs and behaviours (Xue, 2014), and it is just common sense that it is too much and, consequently, should be limited in some way. Therefore, the question here is: What should be taught and what should be left out?

First of all, it should be taken into account that teachers might find legal constraints due to educational legislation. In Spain, however, there is no such problem, since, as was previously mentioned, ICC goals are not explicit at all. Some of them are as follows: reading as a means of acquiring information about different cultures and ways of life; appreciating and valuing the foreign language as a means of communication; knowing the fundamental aspects of the socio-cultural milieu; valuing other ways of organizing experience and of structuring personal relationships; etc. (Real Decreto 1631/2006, 29th December). Therefore, at least in this country, teachers have quite a lot of freedom to introduce those contents they consider more relevant.

According to Byram and Feng (2004, p. 160), «the most conventional and the most criticised dimension of culture teaching is what critics call the facts-oriented approach in which culture is basically viewed as civilisation, the "big C" culture, as well as everyday lives, the "small c" culture». In this model, culture is divided in a series of topics for teaching. The main sources of criticism have been that it might lead to the teaching of stereotypes, and that it does not deal with the social dimension of this construct. However, in spite of that fact, this perspective is still one of the most widespread in language teaching. Some experts (Hu \& Gao, 1997 as quoted in Byram and Feng, 2004, p. 161) consider that "knowing facts is necessary as a starting point for culture learning» and propose an approach which starts by providing learners with more or less stereotypical knowledge, which is then analysed from a critical perspective and compared to a variety of representations of the concept under discussion. In other words, they suggest teaching culture by broadening the learners' views beyond simple stereotypes and by, basically, fostering their critical thought capacities.

Xue (2014), for his part, elaborates on a less ambitious set of contents. In his opinion, what should be taught as part of the ICC is: cultural connotation of words; idioms; cultural factors affecting verbal and non-verbal communication; general knowledge of English-speaking countries; and differences in cultural values and thinking patterns between the target culture and the students'. Xue's proposal seems to be more language-centred than others, which might seem logical to many when dealing with EFL contents. In addition, it might be too general, so, again, too much responsibility would be placed on the teachers' shoulders, since they would have to design a more specific syllabus of their own.

The truth is that most EFL teachers in Spain use textbooks which, to a bigger or lesser extent, contain cultural information. This fact has an 
obvious time-saving advantage and provides a given and, more or less, structured syllabus. Nevertheless, they often present an excessively limited view of the foreign culture and foster stereotypes (Paricio, 2005). In our "real-life" teaching context, a sensible choice seems to be using the existing materials (in the textbook), which are normally more languagefocused, and, at the same time, enrich them by designing cross-curricular projects which can be revised and implemented every year.

When devising a project to teach ICC to EFL students, there are several variables that should be considered, so that the information the learners receive is not biased or incomplete. Teachers can and should check the adequacy of the materials they are using in a number of ways in order to make sure they are appropriate to achieve the learning targets. For example, according to Sercu (1995, p. 140-142), there are four criteria teachers should apply to make sure the materials they are using are suitable to teach ICC. The first criterion is related to representativeness and realism: is the picture of the society complete, up-to-date and realistic? Or does it show an idealistic, "tourism-oriented" view, where conflict does not exist? The second criterion deals with the characters in the book: how is the population depicted in terms of age, ethnicity, social class, mood, behaviour, etc.? The third aspect is language. Educators must check if the language used carries either positive or negative connotations in relation to the different social or ethnic groups. Finally, teachers must take the pupils' role into account, too, and analyse if they are supposed to have a more active, opinion-giving attitude or a more passive behaviour.

\subsubsection{How to teach: methodology}

Most scholars agree that culture learning is more difficult to teach in the classroom context than language (Byram \& Feng, 2004). They assume that interacting "with people who embody a culture, who are native speakers of a language, is crucial» (p. 153). In this sense, they regard study-abroad programmes as opportunities to develop both the learners' linguistic competence and their cultural awareness and intercultural competence. Despite sharing their views, it must be admitted that «our students have never been to any English-speaking countries before they start to learn and use the target language» (Fageeh, 2011, p. 66). As a result, an alternative approach should be proposed, which is valid and reliable for all kinds of learners, from absolute beginners to more advanced students.

Although it has not been fully explored, the internet seems to be a powerful tool for students and teachers to explore diverse ethnographic aspects of the target culture (Byram \& Feng, 2004). In fact, most teenagers (if not all) in Spain are familiar with different English/ American cultural products they can have access to through the internet, such as sitcoms, music, magazines, etc. Consequently, it can be used as an 
effective tool to learn English culture (Fageeh, 2011), both in an independent way and with the teacher's guidance.

Several authors (Fageeh, 2011; Dogancay-Aktuna, 2005; Skopinskaja, 2003; Gray, 2000) agree that, in general terms, encouraging students to adopt a comparative perspective might be an effective way of attaining a two-fold objective. On the one hand, it could be a motivating technique for students to upgrade their knowledge from their own culture. On the other hand, it could help them learn about the similarities and differences between the target culture and their own.

In the context of English as a Foreign Language (EFL), "some authors believe that teaching EFL means more than teaching the language; it also involves learning how to slip into the English culture as smoothly and as naturally as can be possible» (Fageeh, 2011, p. 64). An ideal language learner, then, should end up being both bilingual and bicultural.

In the secondary school context, teachers face the following challenge: developing intercultural communication competence (ICC) together with linguistic competence, so that their students can be competent language users who can get on successfully in the foreign culture. The problem a lot of FL instructors encounter is that, due to different reasons, they find it difficult to teach ICC to their pupils effectively.

After having analysed what ICC is and how it can be taught, we turn to explain a teaching proposal through which teaching IC to secondary students in Spain is aimed at.

\section{Teaching proposal}

This paper aims at supplying some guidelines related to contents and methodology that might be implemented to introduce the teaching of ICC in secondary school. First, a teaching proposal is fully explained, followed by some hints on how to assess the students' performance.

\subsection{Teaching goals}

The teaching proposal that is going to be described has various objectives, which are different in nature. As it has been conceived as a project, that is to say, a series of interconnected tasks, the goals that are sought are diverse. The main ones are:

a) Improving the students' Intercultural Competence (ICC) by fostering their acquisition of knowledge related to the recent historical and socio-cultural background of some English-speaking countries (the big " $\mathrm{C}$ " culture), especially that connected to youth culture. As has already been mentioned, it is generally agreed (Byram and Feng, 2004) that merely teaching bare facts is not enough to improve the learners' ICC, nevertheless, as some authors state (Hu \& 
Gao, 1997 as quoted in Byram and Feng, 2004), it could be a useful starting point for learners to get acquainted with the L2 culture.

b) Motivating students through the use of music and the performance of tasks, so that they start using English as a means of communication. Swain (2013, p. 195) stated that «emotions are an integral part of cognition». This means that all the intellectual processes we engage in are influenced by them and, as well as that, they (emotions) are said to mediate our learning outcomes. Both emotions (affect) and cognition (beliefs), together with behaviour, conform our attitudes towards a specific learning target. In terms of language learning, this means that attitude defines the relationship between a subject (the learner) and an object (the language), and informs us about the subject's disposition towards the object (Espí \& Azurmendi, 1996).

In addition, it has been stated (Gardner and Lambert, 1959) that motivation, that is, the reason or reasons why an individual learns something, has an important role to play in language learning. That reason can have and integrative orientation or an instrumental one. An integrative attitude, initially associated with the learner's interest to identify with the target language community, seems to be an outdated concept in the globalized world of the twenty-first century (Kormos \& Csizér, 2008). In turn, it is said to reflect a desire to learn about the language group and to meet people belonging to it. Instrumental attitudes, in contrast, are represented by utilitarian motives (Gardner \& Lambert, 1959). Although both can be effective in terms of making learners succeed (Ehrman, Leaver \& Oxford, 2003), integratively oriented students are said to be more successful than instrumentally oriented students (Gardner \& Lambert, 1959).

c) Fostering the learners' acquisition of fundamental learning skills that they will need to master in order to ensure they pick up useful techniques which help them improve their lifelong learning skills. For example, students will work in small groups, which will aid them to realize «they can achieve learning goals that would be much more difficult if they had to do it on their own» (García \& Sylvan, 2011, p. 395). Consequently, that experience is believed to enrich their teamwork skills. Other learning skills that are thought to be upgraded are self-assessment, autonomous information search, critical thinking, etc. Furthermore, showing students how to work collaboratively and, then, making them put it into practice, enhances their learning experience, which means that they will learn more and better than being merely passive receivers of input (Kagan, 2009).

In spite of the fact that teaching ICC is the main aim of this teaching proposal, it should not be forgotten that it is part of a subject: EFL. As a 
result, some of the teaching goals that are sought are connected to linguistic criteria. These are namely:

d) Getting the students produce intelligible oral messages, according to their level of proficiency. In order to achieve that goal, the classes will be leaner-centred. This way, the pupils' linguistic opportunities will not be limited, as collaborative dialogue will be employed to develop new linguistic skills (García \& Sylvan, 2011). In this context, the teachers are seen as facilitators of the students' learning process. This means that materials, methods, activities and so on are nearly tailor-made and, as some authors claim, putting students at the centre of the process increases their possibilities to succeed (Cohen, 2003).

e) Amelioration of the pupils' pronunciation. Learners will be provided with plenty of opportunities to listen to authentic oral messages and that input is thought to help them make progress in their own oral skills. It is true that some authors (Cenoz and Gorter, 2011) state that the native speaker as the only ideal for perfection has traditionally been overestimated. However, whenever someone learns something, it is useful to have a 'model' which serves the learner as guidance. In that sense, the idea of the NS could be useful.

\subsection{Description of the proposal}

The proposal that is going to be described takes the history of pop music in several English-speaking countries during the second half of the twentieth century as its leading theme. It has been devised to be implemented in all four different levels in compulsory secondary education (in Spain, ages 12-16). All the classes will carry out the same type of tasks, although each one will be focused on a different decade (60s, 70s, and so on), in terms of central topic and related information. As a result, the first year class (ages 12-13) will focus on the 60s; the second year (ages 13-14), on the 70s; the third year (ages 14-15), on the 80s; and the fourth year (ages 15-16), on the 90s.

Five tasks have been designed to introduce students into the topic on a step-by-step basis, so that they start by grasping general information related to the historical and socio-cultural context they are to learn about. After that, they will focus on specific music icons, as well as on their lives and the messages they transmitted through their songs (if any). Next, they will explore the language and contents of a specific song in detail. Later, watching a film or a documentary will enable students to actually "see with their own eyes" a visual example of some of the things they have been learning about. The last task (the Quiz) is meant to be a revision task aimed at revisiting all the contents that have been covered throughout the project. 


\subsection{The tasks}

In this section, a detailed description of the different tasks the students are going to perform will be provided. Apart from a step-by-step explanation of the assignments, the materials that are necessary to carry them out and the class sessions that might be employed will also be referred to.

\subsubsection{Task 1. The Poster}

The first task has been designed as a broad introduction for students to the historical background they are going to focus on. Most pupils in the first year of secondary education do not have an overall knowledge of the history and culture of the twentieth century, since it has not been studied in primary education (Real Decreto 126/2014, 28th February). As a result, having them glance at what was going on at that time is a way to help them place themselves in context. Moreover, they will be getting high amounts of L2 input, as they will have to read texts, or watch videos, which will help them "warm up" for the following, more demanding activities.

\subsubsection{Task description}

First of all, the class will be arranged in groups of three or four students (depending on the class size). Then, they will be asked to make an internet search to look for information on the main historical and socio-cultural events which took place during the decade they have been assigned. When they have completed their search, they will have to select those episodes that, in their opinion, were the most crucial in the decade. After that, they will have to provide a title or caption for each one of them and a brief summary (three or four lines) which reports it. Also, an image which depicts the event will have to be looked for.

Once all the data have been gathered and organized appropriately, each group will make a poster. First of all, students will be provided with art paper roll, which they will cut out to the size they wish. First, they will draw a timeline sideways, across the middle of the piece of paper, where they will mark all the years in the decade they are working about. On the upper part of the paper, just above the corresponding year in the timeline, the learners will stick each caption, the short texts and the images they have previously prepared, showing the main historical events they have chosen in chronological order. In the lower part of the poster, just below the timeline, they will have to do the same thing, but this time they will have to focus on news related to the cinema, fashion, music and culture of the given decade.

After completing the task, all the posters will be displayed on the classroom walls and each group of students will briefly speak about the importance of the facts they have included in their placard, by explaining 
the rest of the class why they have chosen to depict those specific events, and not others.

\subsubsection{Comparison with students' own culture}

The following step consists of a comparison between what students have learnt about the foreign culture and their own. As has already been mentioned, this is a necessary activity so that learners can analyse data from a critical perspective, so that they go beyond simple stereotypes. In order to carry out this activity, the students, organized as they are (in the same groups), will choose one of the years in the decade they have been researching. After that, each group will do a quick internet search to look for what, in their opinion, was the most important event in their home country (Spain) in that year. As they had previously done, they will provide a title or caption for it and a brief summary (three or four lines) to report it. On top of that, an image which depicts the event will also have to be looked for. Furthermore, each group will have to focus on a specific piece of news related to the cinema, fashion, music and culture which took place at that time.

Once all the pupils have finished, all the students (as a class) will have to make a poster (similar to the one they have previously made), on which each group will stick their information. The result will be a timeline in which they will be able to observe the main events that took place in their country during the given decade, and what was going then in terms of fashion, culture, music, etc. A class discussion will take place after that, in which students will compare what had happened in their country and in the foreign countries at that time. It will be interesting to highlight the similarities and differences between both of them, so that learners can analyse them.

\subsubsection{Task 2. Oral Presentation}

After they have finished Task number 1, learners are expected to have had an initial approach to the most popular singers and/ or bands at the time. Taking that for granted, the second task will be started from that point. This time, they will be working in pairs so that they have more opportunities to interact with each other and with the rest of the class in the $L 2$.

\subsubsection{Task description}

To begin with, the whole class will brainstorm as many music icons (from the time studied) as they can think of and, right after that, the teacher will write a list of their names on the whiteboard. If necessary, the teacher might give them hints to help them place popular artists in the right decade or provide them with names of musicians who are not so familiar to them. 
Next, each pair will choose one of them, after which they will have to prepare an oral presentation (which will last from 6 to 8 minutes), necessarily including the subsequent items: name of the band or singer; brief biography of the singer or individual members of the band; when, how and why they started playing (together, in the case of bands); brief history of their musical career; most important hits. The first session will take place in the computer lab, because learners will probably need to search for information on the internet.

The second class will be employed to design and prepare the presentation. In order to make their presentations more interesting, students will be allowed to use any audio-visual resources that might enrich their performance (power point presentation, sample music, images, short videos and so on). Once they all have finished them, they will have to present their findings to the class and the teacher.

\subsubsection{Comparison with students' own culture}

In order to analyse how the music scene (fashions, interests reflected on the lyrics, etc.) were similar or different in the foreign countries and in Spain, the whole class will brainstorm as many Spanish music stars as they know and the teacher will write a list of their names on the whiteboard. If necessary, the teacher might help them or provide them with names of popular musicians who were successful in Spain at that time.

Next, each pair will choose one of them, after which they will search for information on the internet. They will have to focus on the type of music the chosen singer or band played and the message in their lyrics, as a reflection of popular worries, interests, etc. After that, each pair will briefly expose what they have found out to the rest of the class and a subsequent class discussion will take place, where similarities and differences will be analysed.

\subsubsection{Task 3. Learning with songs}

This task differs from the others that integrate this teaching proposal in that it has a twofold objective, one of which is not directly linked to ICC. On the one hand, it obviously pursues teaching ICC to secondary students, being that the central aim of the proposal. On the other hand, though, we must remember that it has been devised to be integrated as a part of EFL and, as such, attaining linguistic-related objectives is also expected. As a result, there are two parts to the task: the first, which is directly connected to the previously stated teaching goals d) and e) (see section 3.1), and more linguistic in nature; and the second, which focuses more on ICC, as stated in teaching objective a) (see section 3.1).

\subsubsection{Task description}

In order to carry out this task, students will work in pairs (with the same person as in Task 2). Each couple will have to prepare two activities, 
based on the lyrics of a song by the singer or the band they delivered the presentation about. They will be free to choose any song they like, as far as the lyrics have enough "content" to enable them to work with it. The first part will be a listening comprehension activity and the second will be a True/ False exercise.

In the first place, the teacher will show the pupils how to exploit the lyrics of a song for learning purposes. Different options will be dealt with, apart from the traditional "gap-filling exercises", and learners will be able to implement the format they prefer. Some of the model exercises they will learn about will be:

- Gap-filling: certain terms (verbs, prepositions, nouns, etc.) are erased in the lyrics of a song (leaving a "gap"). Then, the students have to listen to it and decide what word has been eliminated and try to complete the lyrics by writing that term.

- Code change: The pupils transcribe the lyrics of a song by using an alphabet which is different from the English one. They can either use an already existing code or devise their own. After providing their classmates with the key, they (their classmates) will have to recover the original lyrics. Then, they will have to listen to the song to check if they have done it correctly or not.

- Writing the opposite: In this model, the lyrics of the song must be re-written by substituting as many words as possible by their antonym (boy-girl, go up- go down, feel blue- feel happy ...). The pupils, then, have to provide the authentic words, after listening to the song.

- Pictograms: Pictograms are used to substitute some or all of the nouns which appear in the lyrics. First, the students will have to work out their meaning and, after that, they will listen to the song in order to check if their deduction was right or wrong.

- Blanks and riddles: Some terms are eliminated from the song. Then, the pupils are provided with a list of riddles (one per each word that has been erased) which they have to guess, in order for them to find out those terms. Finally, they will listen to the song for correction.

- Scrambled lines: Students will jumble the verses in a song. Then, their classmates will have to listen to the song and decide which the correct order for those verses is.

Once the pupils have decided which exercise format they are going to implement, they will have to search the internet and get a copy of the lyrics of the song they are going to work with. Afterwards, they will prepare a worksheet in which they will use those lyrics to prepare a listening comprehension exercise. Apart from that, they will have to make sure that they know the vocabulary and the grammatical structures which appear in the song. In addition, they will have to look for a version of their song that they can use and play in the class. 
Finally, the pupils will take over the teacher's role (in pairs) in the classroom. This way, they will use the handouts they have prepared in order to lead a listening comprehension session with the rest of the class. Pairs will be selected randomly by the teacher.

Once that part of the task has been completed, learners will have to carry out the second part of the task. Here, they will have to ask their classmates to write a short text (about 100 words) in which they will explain what aspect of the historical or socio-cultural context of the time is presented in the song and why, in their opinion, it is dealt with. For instance, if Zombie (The Cranberries, 1994) was dealt with, the students could ask their mates to connect the lyrics of the song to the conflicts in Northern Ireland during the 1990s. Another example could be Fortunate Son (Credence Clearwater Revival, 1969), which would help them consider the issue of the Vietnam War. When they have finished, they will use those texts to set up a ten-minute class discussion in which they will contrast their views.

\subsubsection{Comparison with students' own culture}

After all the songs have been presented to the class, it would be interesting to have each pair of students look for a Spanish song that, from their point of view, reflects a historical or a socio-cultural issue of the time. After that, they can compare what kinds of topics were dealt with in pop music both in and out of Spain and discuss what similarities and differences there were and the reasons why they might have existed.

\subsubsection{The Film}

The aim of this task is to help students put together or internally "summarize" everything they have learnt up to this point. It is intended to help them integrate all the information they have been exposed to and make it more meaningful and comprehensible for all of them.

\subsubsection{Task description}

In the first place, a film or a documentary in English (with English subtitles) will be watched in class. It will be either a musical made at the time studied or a more recent film, which depicts the historical time they have learnt about. Some suggestions for the different levels could be the following:

- 1st ESO (60s): West Side Story/ Documentaries The Beatles or The Rolling Stones;

- 2nd ESO (70s): Saturday Night Fever;

- 3rd ESO (80s): Footloose, The Blues Brothers, Flashdance, Fame;

- 4th ESO (90s): The Commitments. 
After watching the film, students will get together in groups of four people in order to fulfil a comprehension activity (Appendix) related to the film they have watched. When they have completed the activity, answers will be discussed in the classroom with the rest of their classmates.

\subsubsection{Comparison with students' own culture}

It might be interesting to have pupils watch a short clip (part of a film, for example) or documentary depicting the studied decade in their own country. After that, they could establish similarities and differences between both visual documents (the Spanish and the foreign one) and draw conclusions, which could be exposed in the form of a class discussion. At this point, it could be stimulating for students to pay attention to the characters' concerns, the socio-cultural backgrounds depicted in the films and, broadly speaking, what the reasons for those similarities and/ or differences could be.

\subsubsection{The Quiz}

This task is intended to assist students in revising everything they have learnt and done throughout the project. They are asked to stop and go back over all the contents that they have seen.

\subsubsection{Task description}

In the first place, student groups will get together and will write fifteen questions related to anything they have learnt during the project. After that, they will be given fifteen cards, where they will write one question on one side and the answer on the other side of the card. When they have finished, all the groups will give the teacher their cards so that he/ she revises them to avoid repetitions.

During the next class, all the pupils (in groups) will take part in a "Super Quiz". The teacher will shuffle all the cards (about 50-70 per group). Then, he/she will read one question and the student groups will take turns to answer them. The group who gets the right answer, earns a point. If they do not know it or give a wrong answer, the following will give it a try. They have to provide as many correct answers as they can. The group who answers more questions correctly, wins the contest and, as a result, obtains an extra mark.

\subsubsection{Comparison with students' own culture}

This task is based on what learners have been doing throughout the project as a whole. Consequently, it might be a good idea to have them include a few questions highlighting similarities and differences that they have observed in the different sections of the project. 


\section{Assessment}

The final grade the students will obtain, when they have completed the project, will be made up of three components:

- Teacher assessment (60\%): The teacher will assess attainment by providing students with a 0-10 mark for each task, which will be averaged in the end. The criteria that will be implemented for the poster and the oral presentations will be known by the pupils beforehand, since they will be given rubrics where requirements are explained in detail. The song and the film questionnaire will be evaluated in terms of task completion and delivery to the teacher. As for the quiz, only the winning students will get the extra mark.

- Peer assessment (20\%): Each pupil will provide a mark for the students they have been working with (group work and pair work), based on a marking sheet (rubric) provided by the teacher.

Self-assessment (20\%): Each student will assess their own work, using the same rubric they have employed to evaluate their classmates' performance.

\section{Conclusion: expected learning outcomes}

In the first place, the learners' Intercultural Competence is supposed to have improved substantially. They will have read about a variety of historical characters and events, and will have listened to what their classmates have researched about. Furthermore, they will have done some investigation about youth culture and lifestyle in the past, both in foreign countries (probably, most of it will be focused on the UK and the United States) and in their own. They will have had the chance to know about it and compare it with their immediate reality. As a result, they are expected to widen their viewpoints and become more tolerant towards difference.

The students' attitudes and motivation towards other languages and cultures (in this case, English) is expected to improve. Moving the focus away from linguistic correctness and using the topic of music as the driver is supposed to have fostered positive integrative attitudes on learners, since the topic chosen is generally thought to be interesting and motivating for teenagers (Hudson, n.d.). The leading theme of music is considered as the "hook" which will have caught the learners' attention. Besides, having made pupils compare what they have discovered with their own reality is hoped to get them intrigued on the differences, as well as the similarities that they may find.

By carefully designing the different tasks students have to carry out, they are expected to have acquired or, at least, improved their lifelong learning skills. First, they will have worked their teamwork abilities. As a 
result, they will have practiced negotiating, discussing, analysing, etc. Furthermore, they will have had to assess their classmates' performance, as well as their own; consequently, they will have had to critically analyse a series of parameters and decide on their level of correctness, according to them. As well as that, they are thought to have improved their critical thinking skills, by comparing, categorizing, selecting information (in terms of their importance), etc.

Apart from the above-mentioned outcomes, the proposal is supposed to have had a positive impact on the learners' oral skills (listening comprehension, fluency, pronunciation). First of all, students are, in a way, "pushed" to listen to and speak in English. Moreover, as linguistic correctness is not the focus, they are thought to take more risks, since the ultimate goal is successful communication. Moreover, they will have got plenty of authentic input, which is expected to help them improve their pronunciation, intonation, vocabulary range, and so on.

\section{References}

Byram, M. And A. Feng (2004). «Culture and language learning: teaching, research and scholarship». Language Teaching, 37, 149-168.

Celce-Murcia, M. (2007). "Rethinking the role of communicative competence in language teaching». In E. Alcón \& P. Safont-Jordá (eds.) Intercultural language use and language learning. (p. 41-55) Springer Netherlands.

Cenoz, J. AND D. GoRTer (2011). "A holistic approach to multilingual education: Introduction». The Modern language Journal, 95, 339-343.

COHEN, D. H. AND THE FACULTY AND STAFF OF INDEPENDENT DAY SCHOOL (2003). It's all about kids. Every child deserves a teacher of the year. Tampa: Bee Happy Publishing.

Dogancay-AktunA, S. (2005. "Intercultural communication in English language teacher education». ELT Journal, 9, 99-107.

Ehrman, M. E., B. L. Leaver AND R. L. Oxford (2003). "A brief overview of individual differences in second language learning». System 31, 313-330.

EsPí, M. J. \& M. J. AZURMENDI (1996). «Motivación actitudes y aprendizaje del español como lengua extranjera». RESLA, 11, 63-76.

EUROPEAN COMMISSION. (2006). "Recommendation 2006/962/EC of the European Parliament and of the Council of 18 December 2006 on key competences for lifelong learning». Official Journal L 394. Retrieved on February 1st, 2015 from http://europa.eu/legislation_summaries/education_training_youth/lifelo ng_learning/c11090_en.htm 
European Commission. (2007). "Key competences for lifelong learning. European Reference Framework». Luxembourg: Office for Official Publications of the European Communities.

FAgeeH, A. (2011). "At crossroads of EFL learning and culture: How to enhance cross-cultural awareness in EFL college students». Cross-cultural Communication, 7 (1), 62-72.

GarcíA, O. AND C. SyLVAN (2011). "Pedagogies and practices in multilingual classrooms: singularities in pluralities». The Modern Languages Journal, 95: 385- 400.

Gardner, R., \& W. LAMbert (1959). "Motivational variables in secondlanguage acquisition». Canadian Journal of Psychology. Retrieved on 4th April from http://psycnet.apa.org/journals/cep/13/4/266/

Generalitat Valenciana, Conselleria d’Educació, Cultura I Esport. (2014). «El curso 2014-15 comienza con 96.047 alumnos en Castellón, 1.234 más que el pasado curso». Retrieved January 26, 2015 from http://cece.gva.es/es/agenda.asp?id=2729

GRAY, J. (2000). "The ELT coursebook as cultural artifact: how teachers censor and adapt». ELT Journal, 54 (3), 274-282.

Hofstede, G. (1986). "Cultural differences in teaching and learning». International Journal of Intercultural Relations, 10, 301- 320.

Hudson, C. (n.d.). "Go with the flow: 10 ways to easily engage teenagers». Retrieved June 18th 2015 from http://understandingteenagers.com.au/blog/2010/09/go-with-the-flow10-ways-to-easily-engage-teenagers

JoY, S. \& D. A. KOLB (2009). «Are there cultural differences in learning style?» International Journal of Intercultural Relations, 33(1), 69-85.

KAGAN, S. (2009). "Un cambio de paradigma para la educación del siglo XXI». Retrieved February 3rd 2014, from http://talleres.global-learning.es KORMOS, J. AND K. CSIZÉR (2008). «Age-related differences in the motivation of learning English as a foreign language: attitudes, selves, and motivated learning behavior». Language Learning 58, 327-355.

ReAL DeCRETo 1105/2014, 26th December. BOE number 3, 3rd of January, 2015: p. 169-546

ReAl DeCRETo 126/2014, 28th February. BOE number 52, 1st March, 2014: p. 349-420.

Real DeCreto 1631/2006, 29th December. BOE number 5, 5th January, 2007: p. 677-773

PARICIO, M. S. (2005). "La dimensión cultural en los libros de texto de lenguas extranjeras: pautas para su análisis». Glosas Didácticas (15), p. 133-144. 
SERCU, L. (1995) Intercultural Competence. Denmark: Centre for Languages and Intercultural Studies.

SKOPINSKAJA, L. (2003). "The role of culture in foreign language teaching materials: an evaluation from an intercultural perspective». In Lázár, J. (ed.) Incorporating intercultural communicative competence in language teacher education. Strasbourg: Council of Europe.

SWAIN, M. (2011). "The inseparability of cognition and emotion in second language learning». Language Teaching, 46(02), 195-207. doi:10.1017/S0261444811000486

XUE, J. (2014). "Cultivating intercultural communication competence through culture teaching». Theory and Practice in Language Studies, 4 (7), p. 1492-1498.

Young, T. J. AND I. SACHDEV (2011). «Intercultural communicative competence: exploring English language teachers' beliefs and practices». Language Awareness, 20 (2), p. 81-98. 
Appendix. Questionnaire for films

1. Provide a brief summary of the film. (Two or three sentences are fine; you don't need to include a lot of details.

2. State your opinion about the film. What are its strengths and weaknesses? Provide specific examples (scenes, situations) from the film.

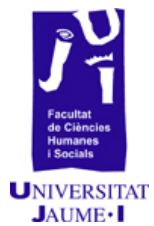

3. What character(s) do you most identify with? What are the main personality traits of this (these) character/s?

4. In your opinion, what was the director's intention or message?

5. How does the film relate to American/ British/ ... culture?Specifically, how does it relate to the era in which it was made?

6. From your point of view, was watching the film useful in order to know more about American/ British/ ... culture? Why? 